Scand. J. of Economics 115(2), 423-448, 2013

DOI: $10.1111 /$ sjoe. 12016

\title{
Why Are Rich Countries More Politically Cohesive?*
}

\author{
Carl-Johan Dalgaard \\ University of Copenhagen, DK-1353 Copenhagen K, Denmark \\ carl.johan.dalgaard@econ.ku.dk
}

\section{Ola Olsson}

University of Gothenburg, SE-405 30 Gothenburg, Sweden ola.olsson@economics.gu.se

\begin{abstract}
We document empirically that rich countries are more politically cohesive than poorer countries. In order to explain this regularity, we provide a model where political cohesion is linked to the emergence of a fully functioning market economy. Without market exchange, the welfare of inherently selfish individuals will be mutually independent. Whoever has greater bargaining power will be willing to make decisions that enhance the productivity of their supporters at the expense of other groups in society. If the gains from specialization are sufficiently large, however, a market economy will emerge. From being essentially noncohesive under self-sufficiency, the political decision-making process becomes cohesive in the market economy, because the welfare of individuals will be mutually interdependent as a result of the exchange of goods.
\end{abstract}

Keywords: Economic growth; market exchange; political cohesion JEL classification: O41; P16

\section{Introduction}

It is well known that richer economies tend to be more politically stable than their less affluent counterparts. Indeed, almost every indicator of political turmoil, ranging from political protests against policies enacted by the current regime to the dramatic case of revolutions, exhibits a negative correlation with prosperity. This fact is often explained, for example, by the degree of fractionalization of society (measured in terms of income inequality, ethnicity, language, or perhaps religious beliefs). It is suggested

\footnotetext{
${ }^{*}$ We would like to thank Toke Aidt, Arne Bigsten, Heather Congdon Fors, Francisco Gonzalez, Johan Stennek, two referees, and seminar participants at the University of Gothenburg, the International Peace Research Institute Oslo, the Ratio Institute, and the Institutions, Public Policy, and Economic Outcomes Workshop in Cambridge for useful comments. O. Olsson gratefully acknowledges financial support from Vetenskapsrådet, SIDA, and WallanderHedelius' Stiftelse.
}

(C) The editors of The Scandinavian Journal of Economics 2013. Published by Blackwell Publishing, 9600 Garsington Road, Oxford, OX4 2DQ, UK and 350 Main Street, Malden, MA 02148, USA. 
as one important reason for the dismal growth performance of Africa, in particular (Easterly and Levine, 1997). However, a relative lack of political stability is not unique to modern-day poor nations. Indeed, we argue here that a link between prosperity and political stability can also be found in the historical record of today's industrialized societies.

It should be uncontroversial to assert that political instability reflects a basic lack of political cohesion between opposing political sides. However, this only raises the following question: why are some countries are more politically cohesive than others? In this paper, we develop a theory of how political cohesion might arise during the process of market integration and economic development.

The central hypothesis that we advance is that the nature of the political struggle between groups is critically affected by the organization of the economy. The paramount institution in this regard is the market institution itself; that is, whether or not (the members of) rival political groups are exchanging goods in a market. We demonstrate that once intergroup market exchange is initiated, the nature of the political process changes and becomes more cohesive. We argue that this theory could shed light on both the historical patterns and the observed cross-country correlation between political cohesion and prosperity. At the more detailed level, the logic of the argument is as follows.

Consider a regime that can be called self-sufficiency. In this regime, individuals are economically fully self-reliant, in the sense that they themselves produce the goods they consume. This regime might be thought to approximate a predominantly subsistence-oriented economy. In the absence of markets where goods are exchanged, the welfare of individuals will be mutually independent. As a result, any redistributive struggle between individuals will be fierce; whoever has greater bargaining power will be willing to make decisions that enhance the productivity of their supporters at the expense of other groups in society.

Now consider, instead, the polar opposite case: a fully developed market economy. In the market environment, rival political groups specialize in the production of different goods and trade with one another. In a historical setting, the political rivalry between merchants (and later manufacturers), on the one hand, and the landed elite (or farmers), on the other, can be thought of as an example of how rival groups might be identified by the type of good produced. ${ }^{1}$ The key insight is that it will no longer be unambiguously in the interest of any political group to make decisions that enhance their own productivity at the expense of other groups in society.

\footnotetext{
${ }^{1}$ In contemporary Africa, opposing political sides are often defined along ethnic lines. However, in some cases, different ethnic groups are, in fact, also distinguishable by the goods that they produce and with which they tend to be associated. An example involving the cocoa-producing Ashanti in Ghana has been presented by Easterly (2002, Chap. 13).
}

(C) The editors of The Scandinavian Journal of Economics 2013. 
The reason is that the market institution produces a price tag on curbing the living standards and productivity of selected groups, that is, higher prices on the goods that they produce and with which they are associated. As a result of market integration, an alignment of interests emerges, and the political process becomes more cohesive because of this. Indeed, as demonstrated in our model, the allocation outcome from political interaction in a market scenario becomes more efficient (in the stylized model, Pareto optimal), and unanimously agreed upon. Hence, in so far as a transition to a market economy occurs, political cohesion ensues, intuitively making political instability and conflict much less likely. Moreover, output per capita rises because of the gains from specialization, and because of more efficient political outcomes. We refer to this state as capitalist cohesion.

In spite of its attractiveness, a transition from self-sufficiency to a market economy might not occur. As illustrated in our model, whether a transition occurs or not depends, among other things, on the gains from specialization. If a group stands to gain only little from trading, yet is politically powerful in autarky, it might not wish to participate in the market, because of its ability to appropriate substantial resources through the political process. As a result, a transition is not viable. Thus, the economy might be caught in what is, effectively, a poverty trap.

As should be clear, this theory is broadly consistent with the contemporary cross-country correlation between income and political cohesion that we document here. The theory suggests, in addition, that causality runs in either direction. On the one hand, economic progress and domestic market exchange enable a transition into a cohesive political climate. On the other hand, a more cohesive political environment enables more efficient political outcomes, which spurs productivity.

While the model we develop does not focus on political instability per se, it should be clear that our theory is related to research that studies the origin of such instability. Consider, for instance, the hypothesis that ethnic divisions are key in understanding political instability (e.g., Easterly and Levine, 1997; Annett, 2001). ${ }^{2}$ At the fundamental level, the present hypothesis and the notion that ethnicity matters for political instability are perfectly reconcilable; a lack of (willingness to) exchange goods could be

\footnotetext{
${ }^{2}$ Ethnic grievances are often (implicitly) assumed to be exogenous in this kind of empirical work. However, under some (economic) circumstances, it might be optimal for politicians to encourage ethnic hatred in order to forward their own objectives. This can induce a relatively rapid change for the worse; see Glaeser (2005) for theory and cases. Moreover, ethic divisions might lead to the dilution of social capital (or trust in others; Alesina and La Ferrara, 2002), which in turn might influence the development of both markets and cohesion (e.g., Guiso et al., 2008). Similarly, religious beliefs have also been shown to affect people's attitudes towards (or trust in) the government, which could influence regime viability (e.g., Guiso et al., 2003).
} 
grounded in ethnic hatred. Therefore, ethnically anchored political disagreements might be perpetuated by a lack of economic interaction of individual groups. At the same time, the two mechanisms might be at work simultaneously, and independently of one another. Hence, in so far as political instability is a symptom of a lack of political cohesion, our theory contributes to a further understanding of why poorer economies tend to be more politically unstable, and why this state of affairs could come at the cost of lower living standards. From this perspective, this paper is related to the body of literature that directly examines the sources of political instability (e.g., Olson, 1963, Alesina and Perotti, 1996; Easterly and Levine, 1997) or civil conflict (Collier and Hoeffler, 2004; Miguel et al., 2004; Olsson, 2007). There are a number of other contributions that are similarly related, and that provide theory and evidence on the consequences of political instability for prosperity or institutional change (e.g., Barro, 1991; Alesina et al., 1996; Acemoglu and Robinson, 2000; Friedman, 2005). ${ }^{3}$

The paper is also related to a (primarily political science) body of literature that studies a phenomenon often referred to as the liberal peace (i.e., democratic and market-oriented countries usually do not fight with each other). ${ }^{4}$ For instance, Mousseau (2003) has proposed that countries where people are engaged in the contractual exchange of goods and services gradually tend to develop liberal norms and values, which in turn strengthen the market economy. On the basis of a statistical analysis of interstate wars 1950-1992, Gartzke (2007) has even claimed that the positive effect of democracy on peace disappears when a variable for financial openness is included. According to Gartzke (2007), we should therefore refer to the link between prosperity and political cohesion as the capitalist peace. Our paper adds to this body of literature by modeling the process of how an internal market economy arises, which is arguably a necessary requisite for subsequent international trade. ${ }^{5}$

\footnotetext{
${ }^{3}$ A major implication of the present paper is that cohesion arises gradually during development. From this perspective, the works of Galor et al. (2009) and Galor and Moav (2006) are related. However, in these papers, a consensus over political choices emerges because of capital-skill complementarity, which makes rival political groups interdependent (i.e., workers and capitalists). The present paper contains a different consensus-creating mechanism the market mechanism itself. See also Caselli and Gennaioli (2008) for a model showing that when a country is politically divided between the winners and losers from a certain reform, these political divisions are smaller if the reform is a market reform, in the sense that it facilitates trade.

${ }^{4}$ This idea goes back, at least, to Adam Smith. For a literature overview and some new evidence, see Mousseau et al. (2003).

${ }^{5}$ Skaperdas and Syranopoulos (2001) have provided a formal statement of this idea. In their analysis, trade between nations does not necessarily lead to peace. Furthermore, the price of the traded good is assumed to be exogenous, whereas endogenous terms of trade (between rival groups or regions) is a key part of our theory.
} 
The paper is structured as follows. In Section II. we present historical and cross-country evidence on the relationship between political cohesion and economic development. In Section III. we develop the model, and in Section IV. we discuss the implications of the model. Finally, we conclude in Section V.

\section{Motivating Evidence}

The central hypothesis of this paper is that political cohesion might emerge endogenously in the process of market integration and economic development. In this section, we begin by documenting that, as a matter of cross-country correlations, richer countries are, on average, characterized by a greater degree of political cohesion. It should be stressed at the outset that we make no attempt to establish causality. Instead, we view the correlation as an interesting stylized fact, which needs to be accounted for. The theory that we develop is capable of doing just that.

In addition to the cross-country exercises, we discuss historical evidence, which suggests that the industrious revolution (not to be confused with the industrial revolution), that is, the gradual commercialization of economic activity, ushered in the beginning of a more politically stable environment in Europe in general, and in the UK in particular. Thus, the historical record provides some suggestive reduced-form evidence of the main mechanism advocated here: as citizens increasingly rely on each other via trade, their welfare becomes intertwined, prompting their political views to converge. As observed in Section I, this kind of convergence of political views might well be an important reason why richer economies tend to be more politically stable than poorer countries.

\section{Cross-Country Data}

A fully satisfactory measure of the extent of political cohesion is probably impossible to construct in light of the huge number of dimensions over which individuals can hold a political view. Hence, we have to make do with a proxy.

In constructing a measure of political cohesion, we rely on survey data from the World Value Survey (WVS). In the WVS, respondents are confronted with a one-to-ten scale, and they are asked:

In political matters, people talk of "the left" and "the right". How would you place your views on this scale, generally speaking?

In order to capture political cohesion, first we calculate the percentage of respondents who put themselves at the two extremes (i.e., the fraction 
of respondents who answered either one or ten). Political cohesion is then thought to be rising if the fractions of respondents at the extremes shrink. Hence, the variable, political cohesion, is defined as $100-$ (the fraction of respondents answering one or ten). In order to obtain as large a country sample as possible, we have used the results from pooling WVS from the period 1981-2000. ${ }^{6}$

It should be clear that the notion of left and right unquestionably differs from one country to the next. For instance, a right-wing politician in Scandinavia is a completely different sort of character than a rightwing politician in the US. At the same time, it is clear that individuals who answer one or ten are deliberately signaling extreme political views in the context of their local political landscape. Hence, the existence of fewer extremists seems to be a context-independent measure of political distance between the members of any given population, or of a greater degree of political cohesion. Accordingly, whereas we recognize that the absolute scale of political views cannot be compared across countries, we maintain that deviations from the (country-specific) center is a comparable measure of the extent of political cohesion. As a parsimonious measure of economic development, we employ gross domestic product (GDP) at purchasing power parity (PPP) per capita. Because our political cohesion variable reflects surveys from the period 1981-2000, we employ GDP per capita at roughly the mid-point (i.e., 1990). ${ }^{7}$

Figure 1 shows the simple correlation between our measure of political cohesion and GDP per capita. As is visually obvious, the two variables are highly correlated. The amount of variation in the political cohesion variable is noteworthy: for the poorest countries in the sample, it is not uncommon to find 30 percent or more of the population at the political extremes. By contrast, in rich places such as Germany, Austria, and Norway, less than 10 percent of the population feel that they are either extreme leftist or extreme right-wing. We can also observe three major outliers in the figure: Vietnam, Tanzania, and Pakistan. Whereas Vietnam and Tanzania are characterized by very low levels of cohesion, Pakistan is uncommonly cohesive for its income level. In order to examine the robustness of the correlation between cohesion and prosperity, we resort to (outlier robust) regression analysis.

As far as we are aware, only Lindqvist and Östling (2010) have previously examined the determinants of political cohesion. ${ }^{8}$ Like them, we include ethnic fractionalization as an explanatory variable, but we also

\footnotetext{
${ }^{6}$ The data can be obtained online at http://www.worldvaluessurvey.org/.

${ }^{7}$ We have also experimented with using firms per capita instead of GDP as a measure of market development. This indicator is also strongly correlated with cohesion; results are available upon request.

${ }^{8}$ Their indicator of cohesion is also based on questions in the WVS. However, their ultimate dependent variables are economic and government performance, while they model political
}

(C) The editors of The Scandinavian Journal of Economics 2013. 


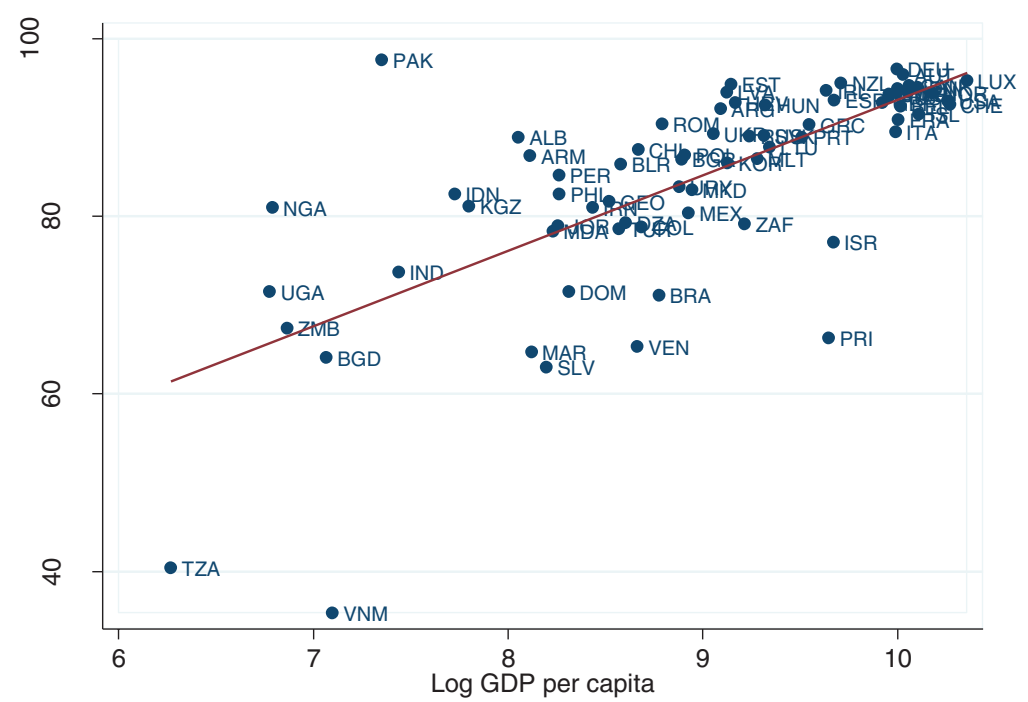

Fig. 1. Political cohesion versus log GDP per capita, for 71 countries. Political cohesion is measured over the period 1981-2000, whereas GDP per capita is measured in 1990. The line in the figure is estimated by OLS. The correlation between the two variables is 0.67 , and significant at 1 percent. Source: World Value Surveys and World Development Indicators

include religious and linguistic fractionalization. In addition, we include variables suggested by the literature on political instability in the control set (e.g., Alesina and Perotti, 1996; Annett, 2001): the urbanization rate, primary schooling, and measures of income inequality or skewness. We also check robustness against the inclusion of population size and age composition of the population, plus a full set of continent fixed effects. Because we use data from the WVS over the period 1981-2000, we measure the controls mid-period, in $1990 .{ }^{9}$ All data on the controls are from the World Development Indicators. ${ }^{10}$ Table 1 reports the results; in all columns, the model is estimated by least absolute deviations; an outlier robust estimator. ${ }^{11}$

Column 1 shows the basic link between GDP per capita and political cohesion; GDP per capita is highly significant. If we were to take the point estimate at face value, it would suggest that a one standard deviation

polarization as an (endogenous) independent variable. Their key instrument for political polarization is ethnic fractionalization.

${ }^{9}$ However, our measures of income inequality (the Gini index) and skewness (the third quintile share) are average values for the period 1980-2000.

${ }^{10}$ The database is publicly accessible from http://data.worldbank.org/data-catalog/worlddevelopment-indicators.

${ }^{11}$ As it turns out, the ordinary least-squares results are very similar (available upon request). 


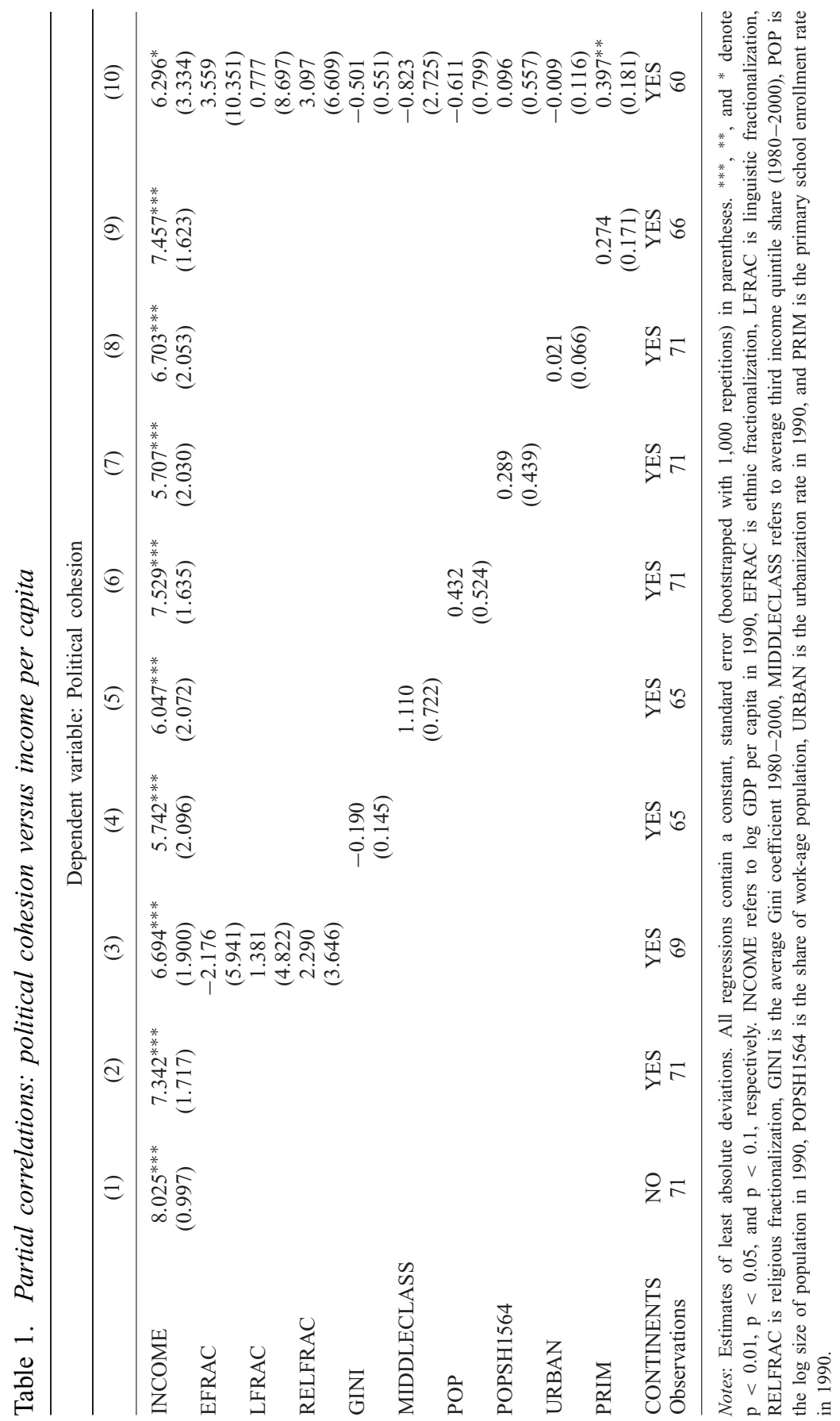

(C) The editors of The Scandinavian Journal of Economics 2013. 
increase in $\log$ GDP per capita increases cohesion by about 0.7 percentage points. In practise, of course, the correlation might well reflect reverse causality and omitted variables. To check for the latter, in the next nine columns, we show how the partial correlation between GDP per capita and cohesion is affected by including additional controls. The point estimate of interest remains fairly stable throughout, and GDP per capita retains its significance in all cases; only when we include all the covariates simultaneously does the significance decline to 10 percent.

Naturally, these results do not establish that GDP per capita increases political cohesion; political cohesion might well be influencing GDP per capita. This is actually the main result in the empirical study by Lindqvist and Östling (2010). ${ }^{12}$ Indeed, according to the proposed theory we would expect this to be the case. In addition, the theory does not imply that GDP per capita matters for cohesion per se; it is the process of specialization and the development of market exchange that influence the political process. Still, as these developments work to elevate living standards, we expect GDP per capita to be a reasonable proxy. Nevertheless, to gain some additional motivation for the advocated mechanism (i.e., linking GDP per capita and political cohesion), we next turn to the historical record.

\section{Historical Record}

Consider England, the epicenter of the industrial revolution. As pointed out by Clark (1996, p. 568), "between 1560 and 1770, England experienced numerous periods of political turmoil, internal warfare, and important changes of political regime." Indeed, this period contains events such as the English Civil War (1639-1651), several planned coups, and the Glorious Revolution of 1688. In fact, most of mainland Europe was characterized by a similar state of affairs during this period. De Vries (1976, p. 3) has put it succinctly: "the seventeenth century is marked by an unusual number of civil disturbances: aristocratic protests against the growth of the bureaucratic state and peasant revolts against new taxes, changed land tenure conditions, and food distribution measures that offended a sense of economic justice."

When moving beyond the seventeenth century, we continue to observe disruption on a fairly regular basis in England. In the eighteenth and early nineteenth centuries, England witnessed the Gordon Riots of 1780, the Luddite movement, the 1776 American Revolution, food riots, and a considerable assortment of minor uprisings (Archer, 2000). Eventually,

\footnotetext{
${ }^{12}$ Lindqvist and Östling (2010) have also found that political cohesion appears to have a negative effect on the provision of public goods as measured by infant mortality rates and infrastructure quality.
} 
however, England did enter a period of calmer political climate towards the end of the nineteenth century, and continued on the path towards prosperity (Olson, 1963). ${ }^{13}$ However, clearly the historical record demonstrates that the political climate in England used to be turbulent, with periods of political upheavals not unlike what is observed in modern-day less-developed economies.

In the context of the historical record, we might wonder whether a transition from self-sufficiency to market trade can be said to have a bearing on what occurred in Europe in general, and in England in particular, during the last millennium. To be sure, there is no historical period where autarky can be said to be an exact description of how the economy was organized. At least as far back as the Dark Ages, archeological evidence of formal market places can be marshaled (Hodges, 1982, Chap. 9), and during the Medieval period, historical evidence shows how markets in England expanded and contracted as a function of the time-varying size of the population (Britnell, 1993). Still, there is no doubt that the last millennium has seen a remarkable expansion of the role of the market in people's everyday lives. As Seabright (2004, p. 42) has put it: "Until around six hundred years ago in Europe, and until a little more recently in North America, most families ate food they had grown themselves. They were certainly not selfsufficient in the strict sense since they relied on others for some things metal for agricultural tools for example. But changes in their links with the outside world would rarely threaten their food supply. Today, in the same countries, most families who were prevented from exchanging with others would starve within a few weeks."

From this perspective, if we think about the current organization of the economy - where individuals, to an extreme extent, rely on each other (or rather the market) for their survival - as a fully integrated market economy, the simplification of describing the situation in Europe a millennium ago as autarky might seem less unreasonable as a (perhaps crude) approximation. ${ }^{14}$

Turning to the crux of the historical theoretical argument, a reasonable case can be made that market participation and the exchange of goods did accelerate in the centuries preceding the industrial revolution, thus paving

\footnotetext{
${ }^{13}$ The fact that contentious gatherings in England gradually became less violent, consistent with greater political cohesion, has also been convincingly documented by Tilly $(2008$, table $8.1)$.

${ }^{14}$ The notion of a clean switch from autarky to a full market economy is a similar (over)simplification. Historically, the expansion of trade over increasing distances was probably gradual (e.g., North, 1991). This gradual evolution covering periods of partial specialization in the economy is not captured by the model. The provision of a more detailed description of the evolution of the market institution and its gradual effects on the nature of the political struggle is a topic for future research.
} 
the way for a more cohesive political climate. The intensification of market participation, associated with a gradual reduction in the degree to which individuals were self-sufficient with regards to agricultural goods, is what De Vries (1994) has called the industrious revolution. In particular, he has remarked that (p. 257): “... the industrious revolution, for which evidence can be found from the mid-seventeenth century into the early nineteenth, consisted of two transformations: the reduction in leisure time ... and the allocation of labor from goods and services for direct consumption to marketed goods."

Moreover, as for the other half of society (i.e., the city dwellers), Voth (1998) has provided evidence of a large increase in working hours in the eighteenth and nineteenth centuries for Londoners. With less time to spare, the urban population would naturally have to become correspondingly more reliant on (increasingly specialized) food producers in order to sustain themselves. ${ }^{15}$

Seen through the lenses of the theory advanced in the present paper, once the industrious revolution is complete, resulting in an intensified exchange of goods, the political climate should start to become more cooperative in nature, as it arguably did in England, starting sometime in the last half of the nineteenth century.

In a similar vein, Friedman (2005) has argued that economic growth for broad segments of society has typically been strongly associated with greater openness, more tolerance, and more democracy. Apart from the UK, Friedman has discussed developments during the last two centuries in the US, Germany, and France. The German experience is perhaps the most striking, with the unification in 1990 happening after an extended period of West German export-led growth, whereas the rise of the extremely noncohesive Nazi rule in the 1930s was largely a reaction to the collapse of a functioning market economy during the Weimar Republic.

\section{The Model}

Consider an economy with a population that is randomly distributed across some land area. Their preferences are defined over the consumption of two different goods. The two goods are labeled "a" and "m", respectively; to fix ideas, we can think of these as agricultural and manufactured goods. There are two groups or regions in the economy: North (n) and S (s). North has a comparative advantage in producing manufactured goods, whereas South has a comparative advantage in agriculture, as specified below. The

\footnotetext{
${ }^{15}$ However, see Clark and Van der Werf (1998) for a skeptical assessment of the claim that working hours expanded during this period.
}

(C) The editors of The Scandinavian Journal of Economics 2013. 
populations in the two regions interact with the purpose of dividing a scarce resource between them.

The overall sequence of events in the model is the following.

(i) The two groups choose what economic regime they prefer to be in: self-sufficiency $(S)$ or market economy $(M)$, that is, whether or not they wish to engage in trade with each other.

(ii) The groups divide up a common productive resource $(R)$ between them through political bargaining, conditional on the economic regime chosen in the first stage.

(iii) The two groups decide how much to produce and consume (and potentially trade), using the allocation of $R$ determined in the second stage.

As usual, we assume rational individuals who can perfectly assess the effects of choices in each stage. The model is solved through backward induction. Therefore, we start by solving for the production and consumption decisions in the third stage.

\section{Preferences}

Let us assume that the population in South is $L_{\mathrm{s}}$ and that the population in North is $L_{\mathrm{n}}$, so that the total population in the country is $L=L_{\mathrm{s}}+L_{\mathrm{n}}$. Once individuals are settled in an area, they remain immobile. For simplicity, we also assume that population levels remain constant throughout the analysis. $^{16}$

Individuals living in region $i=\mathrm{s}, \mathrm{n}$ have the following utility function,

$$
U_{i}=U\left(c_{i \mathrm{a}}, c_{i \mathrm{~m}}\right)=c_{i \mathrm{a}}^{\alpha} c_{i \mathrm{~m}}^{\beta}, \quad i=\mathrm{s}, \mathrm{n},
$$

which depends on the consumption of agricultural goods $c_{i \text { a }}$ and on manufacturing goods $c_{i \mathrm{~m}}$, where exponents $\alpha+\beta=1$ indicate the relative utility of each good. The utility function satisfies the usual assumptions of a positive but diminishing marginal utility of each good. For simplicity, we further assume that individuals are myopic.

All individuals have one unit of time at their disposal for productive activities. In a regime where individuals are self-sufficient, they will split their time between production of the two goods. Accordingly, individuals are subject to the time constraint

$$
1=x_{i \mathrm{~m}}+x_{i \mathrm{a}}
$$

where $x_{i j}$ represents time allocated to the production of good $j=\mathrm{a}, \mathrm{m}$ in region $i=\mathrm{s}$, n.

\footnotetext{
${ }^{16}$ The model can be generalized to allow fertility to be endogenous without implications for the key results.
}

(C) The editors of The Scandinavian Journal of Economics 2013. 


\section{Production}

The production technologies are

$$
\begin{gathered}
m_{i}=R_{i} x_{i \mathrm{~m}}^{\gamma_{i}}, \\
a_{i}=R_{i} x_{i \mathrm{a}}^{\delta_{i}}=R_{i}\left(1-x_{i \mathrm{~m}}\right)^{\delta_{i}},
\end{gathered}
$$

where $m_{i}$ is the output of manufactured goods produced by an individual in region $i, a_{i}$ is the output of agricultural goods produced by an individual in $i$, and $R_{i}$ is the amount of a resource that can be used in both types of production in a given region. As discussed further later, $R_{\mathrm{S}}+R_{\mathrm{n}}=R$, where $R$ is the fixed supply of the resource. Throughout history, land has probably been the most important factor of production. It has also frequently been the object of distributive struggles and weakly defined private property rights. Minerals and fuels are other examples of contestable resources. We can also think of $R$ more broadly as an excludable public good, such as infrastructure, which tends to be supplied via a central government rather than via the market. The other factor of production is time $x$, which is subject to diminishing returns because the output elasticities are given by $\gamma_{i}, \delta_{i}<1$. Unlike the resource $R_{i}$, we assume that an individual's time is not a contestable resource between regions.

A key assumption is that people in the two regions have a comparative advantage in producing one of the two goods. More specifically, we assume that

$$
\gamma_{\mathrm{n}}=\delta_{\mathrm{s}}>\gamma_{\mathrm{s}}=\delta_{\mathrm{n}}
$$

In other words, in North, the marginal productivity of an additional working hour is larger in the m-activity (manufacturing) than in the a-activity (agriculture) $\left(\gamma_{\mathrm{n}}>\delta_{\mathrm{n}}\right)$. Conversely, in South, $\delta_{\mathrm{s}}>\gamma_{\mathrm{s}}$. For simplicity, we assume that there is a symmetry in these productivity differences.

In order to ensure the emergence of comparative advantages in production, we assume that output elasticities and the Cobb-Douglas utility parameters are defined by the following inequality:

$$
\frac{\delta_{\mathrm{s}}}{\gamma_{\mathrm{s}}}>\frac{\beta}{\alpha}>\frac{\delta_{\mathrm{n}}}{\gamma_{\mathrm{n}}} \text {. }
$$

\section{Optimization under Self-Sufficiency}

As discussed above, there are two basic regimes for organizing production in the aggregate economy: self-sufficiency (i.e., people in both regions produce and consume both goods in isolation from each other) and a 
market economy (i.e., trade between locations takes place and production is specialized).

Under self-sufficiency, $c_{i \mathrm{~m}}=m_{i}$ and $c_{i \mathrm{a}}=a_{i}$ (i.e., people in $i$ consume only goods produced in their own region). Thus, the utility maximization problem is to find, for both regions $i=\mathrm{a}, \mathrm{m}$, the allocation of time that maximizes utility:

$$
x_{\mathrm{m} i}^{*}=\arg \max \left\{\left[R_{i}\left(1-x_{i \mathrm{~m}}\right)^{\delta_{i}}\right]^{\alpha}\left(R_{i} x_{i \mathrm{~m}}^{\gamma_{i}}\right)^{\beta}\right\} .
$$

The straightforward solutions to the time allocation problem are

$$
x_{\mathrm{a} i}^{*}=\frac{\alpha \delta_{i}}{\alpha \delta_{i}+\beta \gamma_{i}}, \quad x_{\mathrm{m} i}^{*}=\frac{\beta \gamma_{i}}{\alpha \delta_{i}+\beta \gamma_{i}}, \quad \text { for } i=\mathrm{a}, \mathrm{m},
$$

implying an indirect utility under self-sufficiency (with an index $S$ ) of

$$
V_{i}^{\mathrm{S}} \equiv \Omega_{i} R_{i} \quad \text { for } i=\mathrm{a}, \mathrm{m} .
$$

Here,

$$
\Omega_{i}=\frac{\left(\alpha \delta_{i}\right)^{\alpha \delta_{i}}\left(\beta \gamma_{i}\right)^{\beta \gamma_{i}}}{\left(\alpha \delta_{i}+\beta \gamma_{i}\right)^{\alpha \delta_{i}+\beta \gamma_{i}}}>0 .
$$

The key insight from this expression is simply that indirect utility in region $i$ will depend crucially on resources allocated to region $i$. Because there is no trade, the utilities of North and South are independent from each other.

\section{Optimization in a Market Economy}

In this section, we restrict our attention to the regime where trade takes place between regions, and where people specialize in production according to their comparative advantages. That is, as a result of the different comparative advantages described in the previous subsection, individuals in North might eventually find it beneficial to specialize in the production of manufactured goods (m), while individuals in South specialize in the production of agricultural goods (a).

While the preferences of individuals are the same as under selfsufficiency, the budget constraints are now different. For individuals in region $i=\mathrm{n}$, the total income, $y_{\mathrm{n}}$, is divided between consumption of $\mathrm{m}$ and a-goods:

$$
y_{\mathrm{n}}=c_{\mathrm{nm}}+p c_{\mathrm{na}},
$$

where $p$ is the price of agricultural goods measured in terms of manufactured goods. In North, people's incomes derive from spending the entire time endowment on production of m-goods so that $x_{\mathrm{nm}}=1$. This means 
that total income is equal to the value of total production:

$$
y_{\mathrm{n}}=R_{\mathrm{n}} \text {. }
$$

For people in South, the corresponding constraints are

$$
y_{\mathrm{s}}=c_{\mathrm{sa}}+p c_{\mathrm{sm}}=p R_{\mathrm{s}} .
$$

The solution of the utility maximization problem of individuals in the two regions leads to the following demand equations for the two products:

$$
c_{i \mathrm{~m}}=\frac{\beta y_{i}}{\alpha+\beta}, \quad c_{i \mathrm{a}}=\frac{\alpha y_{i}}{p(\alpha+\beta)}, \quad \text { for } i=\mathrm{n}, \mathrm{s} .
$$

In a competitive equilibrium, relative aggregate supply in the economy equals relative aggregate demand, and the price adjusts so as to clear markets:

$$
\frac{R_{\mathrm{n}} L_{\mathrm{n}}}{R_{\mathrm{s}} L_{\mathrm{s}}}=\frac{[\beta /(\alpha+\beta)]\left(y_{\mathrm{n}} L_{\mathrm{n}}+y_{\mathrm{s}} L_{\mathrm{s}}\right)}{(1 / p)[\alpha /(\alpha+\beta)]\left(y_{\mathrm{n}} L_{\mathrm{s}}+y_{\mathrm{s}} L_{\mathrm{n}}\right)} .
$$

Here, $y_{\mathrm{s}} L_{\mathrm{s}}$ is total aggregate income in South and $y_{\mathrm{n}} L_{\mathrm{n}}$ is aggregate income in North.

After some rearrangements, we obtain the equilibrium price

$$
p^{*}=\frac{\alpha}{\beta} \frac{R_{\mathrm{n}} L_{\mathrm{n}}}{R_{\mathrm{s}} L_{\mathrm{s}}} .
$$

The expression shows that the price for agricultural goods produced in South will increase with $R_{\mathrm{n}}$ because a higher $R_{\mathrm{n}}$ means a corresponding lower level of $R_{\mathrm{S}}$ (because $R_{\mathrm{n}}=R-R_{\mathrm{S}}$ ). This decreases the production of agricultural goods and increases the price.

Using equations (9) and (10) and the regional income expressions $y_{\mathrm{n}}=$ $R_{\mathrm{n}}$ and $y_{\mathrm{s}}=p R_{\mathrm{s}}$, we can solve for the indirect levels of utility in the market economy:

$$
\begin{gathered}
V_{\mathrm{s}}^{\mathrm{M}}=\left[\frac{\alpha y_{\mathrm{s}}}{p^{*}(\alpha+\beta)}\right]^{\alpha}\left(\frac{\beta y_{\mathrm{s}}}{\alpha+\beta}\right)^{\beta}=\alpha R_{\mathrm{s}}^{\alpha} R_{\mathrm{n}}^{\beta}\left(\frac{L_{\mathrm{n}}}{L_{\mathrm{s}}}\right)^{\beta} ; \\
V_{\mathrm{n}}^{\mathrm{M}}=\left[\frac{\alpha y_{\mathrm{n}}}{p^{*}(\alpha+\beta)}\right]^{\alpha}\left(\frac{\beta y_{\mathrm{n}}}{\alpha+\beta}\right)^{\beta}=\beta R_{\mathrm{s}}^{\alpha} R_{\mathrm{n}}^{\beta}\left(\frac{L_{\mathrm{n}}}{L_{\mathrm{s}}}\right)^{-\alpha} .
\end{gathered}
$$

From these expressions, it is immediately clear that the utility of people in region $i$ will be directly dependent on the level of resources in their own region, as well as on the corresponding levels in the other region. This is the primary vehicle behind the emergence of a more cohesive political climate, as described in the following subsection. 


\section{Bargaining Outcomes}

As mentioned above, the political struggle takes place in the second stage over the allocation of the resource $R=R_{\mathrm{s}}+R_{\mathrm{n}}$. The political process for dividing the resource is Nash bargaining, which is employed during both self-sufficiency and market economy. ${ }^{17}$ We assume, for simplicity, that this scenario can be described by the following asymmetrical Nash bargaining problem:

$$
\max _{R_{\mathrm{s}}, R_{\mathrm{n}}} N^{z}=\left(V_{\mathrm{s}}^{z}-d_{\mathrm{s}}^{z}\right)^{\pi}\left(V_{\mathrm{n}}^{z}-d_{\mathrm{n}}^{z}\right)^{1-\pi}, \quad \text { for } z=\mathrm{S}, \mathrm{M} .
$$

In this expression, $V_{i}^{z}$ represents the indirect utility levels in regime $z=$ $\mathrm{S}, \mathrm{M}$ for region $i=\mathrm{s}, \mathrm{n}$ that were derived above, $d_{i}^{z}$ are the disagreement or threat points if bargaining breaks down, and $\pi$ is the (exogenous) relative bargaining power of South.

More formally, $d_{i}^{z} \geq 0$ represents the (exogenously given) utility when the two players fail to agree on some distribution of $R$. It is easiest to think of this as a civil war outcome that is more or less costly. In the following analysis, we make the simplifying assumption that an open conflict is associated with a total loss of $R$ to both players in any regime, such that $d_{\mathrm{s}}^{\mathrm{S}}=d_{\mathrm{s}}^{\mathrm{M}}=d_{\mathrm{n}}^{\mathrm{S}}=d_{\mathrm{n}}^{\mathrm{M}}=0 .{ }^{18}$ Given this extremely undesirable open-conflict scenario, the players will always agree on dividing up the resource in peace, although the outcome of this division might be either cohesive or non-cohesive. A further implication of this assumption is that players cannot use autarkic self-sufficiency as a fallback option in the second stage should they fail to reach an agreement in a market economy. ${ }^{19}$

\footnotetext{
${ }^{17}$ To describe the contest over resources as a Nash bargaining process is admittedly only one among several possible modeling techniques. For instance, instead, we might have employed a conflict theory model, as in Grossman and Kim (1995). Nash bargaining is particularly useful as an equilibrium selection mechanism in the presence of multiple equilibria. See Binmore et al. (1986) for a well-known discussion of the general properties of Nash bargaining models.

${ }^{18} \mathrm{An}$ alternative interpretation is that the common resource is grabbed by a third party, in case the two groups fail to reach a solution. In a competitive international setting, such as late medieval Europe, it was for instance common for internally disunited countries to be swallowed by better organized neighbors.

${ }^{19}$ Returning to self-sufficiency might seem to be a possible bargaining threat point during a market economy, yet in the spirit of Binmore et al. (1986), we argue that it is not. Players first choose what economic regime they wish to be in, and then in the second stage, they divide $R$ by bargaining. In the short run, switching economic regime is not an option, and $d_{i}^{z}$ should reflect the costs, during a particular regime, for not agreeing. When the three stages of the game are played again by a later generation, one or both agents might, of course, choose in the first stage to revert back to the self-sufficiency regime, as discussed in a later section. However, given the structure of our model, this can only happen if we allow for an exogenous shock.
} 
Relative bargaining strength $\pi$ might, for instance, reflect relative sizes of population $L_{\mathrm{s}} / L_{\mathrm{n}}$ or differences in initial wealth, perhaps originating from differences in the relative initial levels of human capital. The parameter might alternatively be thought of as describing some other exogenous source of bargaining strength, such as military power or historical privileges. $^{20}$

The specific formalization in equation (13) should be regarded as a metaphor for something more general. The objective of any political player is (at least, in part) to obtain gains for their supporters. Sometimes, political decisions represent Pareto improvements, but just as often it holds that one group's gain is another's loss. While gains and losses, in general, are not necessarily symmetrical, the simple formalization of a Nash bargain over a scarce resource captures the flavor of non-violent political struggle, the outcome of which affects the income and productivity of the citizens of society. In the case of self-sufficiency, it can be shown that by using equation (7) we can actually reformulate the indirect utility of South $V_{\mathrm{s}}^{\mathrm{S}}$ as a negative, linear function of the indirect utility of North $V_{\mathrm{n}}^{\mathrm{S}}$ as $V_{\mathrm{s}}^{\mathrm{S}}=$ $\Omega_{\mathrm{s}}\left(R-V_{\mathrm{n}}^{\mathrm{S}} / \Omega_{\mathrm{n}}\right)^{21}$

The two opposing political parties will be (representatives from) the two different regions South and North. In a regime characterized by the absence of trade between regions, we can think of political groups as being organized on a regional basis.

The solution to the maximization problem above leads to the following proposition.

Proposition 1. (No Political Cohesion). Assuming that $d_{a}^{\mathrm{S}}, d_{m}^{\mathrm{S}}=0$, the bargaining solution under self-sufficiency is $R_{\mathrm{s}}^{*}=\pi R, R_{\mathrm{n}}^{*}=(1-\pi) R$. The bargaining power of the political groups determines allocations.

Proof: The bargaining problem under self-sufficiency when $d_{\mathrm{s}}^{\mathrm{S}}=d_{\mathrm{n}}^{\mathrm{S}}=0$ is to find $R_{\mathrm{n}}^{*}=\arg \max \left\{N^{\mathrm{S}}=\left[\Omega_{\mathrm{s}}\left(R-R_{\mathrm{n}}\right)\right]^{\pi}\left[\Omega_{\mathrm{n}} R_{\mathrm{n}}\right]^{1-\pi}\right\}$, where the terms inside the brackets (when multiplied by the bunch of parameters $\Omega_{i}$ ) are the indirect utilities derived above. The usual steps lead to the solution stated above.

Hence, the division of the resource will simply reflect the relative political power of the two regions or groups. If one region were to become disproportionately powerful, nothing rules out a solution where it would

\footnotetext{
${ }^{20}$ We might also have imagined that both groups invested time or other resources in improving bargaining strength $\pi$ in a previous stage, as in the labor-market model of Aidt and Sena (2005).

${ }^{21} \mathrm{~A}$ short proof of this result is the following. From equation (7), we know that $V_{i}^{\mathrm{S}}=$ $\Omega_{i} R_{i}$, and hence that $R_{\mathrm{n}}=V_{\mathrm{n}}^{\mathrm{S}} / \Omega_{\mathrm{n}}$. Using this result for $R_{\mathrm{n}}$ implies that $V_{\mathrm{s}}^{\mathrm{S}}=\Omega_{\mathrm{s}} R_{\mathrm{S}}=$ $\Omega_{\mathrm{s}}\left(R-R_{\mathrm{n}}\right)=\Omega_{\mathrm{s}}\left(R-V_{\mathrm{n}}^{\mathrm{S}} / \Omega_{\mathrm{n}}\right)$.
} 
take most of the resource for itself, leaving the other region to starvation. In this sense, the political struggle is non-cohesive because the two individual factions of society simply attempt to grab as large a fraction of the resource as possible for their own benefit. ${ }^{22}$

Let us now turn to the division of the resource under a market economy. After substituting for the indirect utility levels of the two groups from equations (11) and (12) into the Nash bargaining function, and recalling that $d_{\mathrm{s}}^{\mathrm{M}}, d_{\mathrm{n}}^{\mathrm{M}}=0$, it follows that the bargaining problem in a market economy becomes that of finding

$$
\begin{aligned}
R_{\mathrm{n}}^{* *} & =\arg \max \left\{N^{\mathrm{M}}=\left[\alpha R_{\mathrm{s}}^{\alpha} R_{\mathrm{n}}^{\beta}\left(\frac{L_{\mathrm{n}}}{L_{\mathrm{s}}}\right)^{\beta}\right]^{\pi}\left[\beta R_{\mathrm{s}}^{\alpha} R_{\mathrm{n}}^{\beta}\left(\frac{L_{\mathrm{n}}}{L_{\mathrm{s}}}\right)^{-\alpha}\right]^{1-\pi}\right\} \\
& =\arg \max \left[\alpha^{\pi} \beta^{1-\pi}\left(\frac{L_{\mathrm{n}}}{L_{\mathrm{s}}}\right)^{\pi-\alpha}\left(R-R_{\mathrm{n}}\right)^{\alpha} R_{\mathrm{n}}^{\beta}\right] .
\end{aligned}
$$

In the same manner as above, we obtain the following key result.

Proposition 2. (Political Cohesion). Assuming $d_{\mathrm{s}}^{\mathrm{M}}, d_{\mathrm{n}}^{\mathrm{M}}=0$, the bargaining solution in the market economy is $R_{\mathrm{s}}^{* *}=\alpha R, R_{\mathrm{n}}^{* *}=\beta R$. The solution is unanimously agreed upon by the two regions.

Proof: A straightforward differentiation of the Nash product above yields the results.

Hence, in the market regime, the division of bargaining power $\pi$ ceases to be relevant for the solution to the bargaining problem. Because both regions will want to maximize the term $R_{\mathrm{s}}^{\alpha} R_{\mathrm{n}}^{\beta}, \pi$ drops out of the above equation. Each player's utility is also dependent on the other player's access to resources. In effect, the result is equivalent to choosing an allocation for $R$ that maximizes the sum of the utility for the two groups. In other words, the outcome from the bargaining process will be unanimously agreed upon and will be Pareto optimal.

The intuition for this result is simple. In both regions, individuals value agricultural and manufacturing goods to the same extent ( $\alpha$ and $\beta$ are the same in both regions). Hence, they share the same preference for maximizing output of the two goods, and desire a low price for each. The utility levels of individuals in the two regions thus become linked via the market mechanism. ${ }^{23}$ Seen from the perspective of, say, people in South,

\footnotetext{
${ }^{22}$ However, it should be pointed out that, by construction, Nash bargaining solutions are always Pareto efficient.

${ }^{23}$ Indeed, it can be shown that $V_{\mathrm{n}}^{\mathrm{M}}=V_{\mathrm{s}}^{\mathrm{M}}\left(\beta L_{\mathrm{s}} / \alpha L_{\mathrm{n}}\right)$; that is, the indirect utility of North is now a positive linear function of that of South, and vice versa.
} 
the productivity of manufacturing in North becomes important, because this determines the price that Southerners have to pay for manufactured goods. Likewise, individuals in North will worry about the price of agricultural goods, and therefore also about the productivity of the people in South. This state of affairs leads to a commonly agreed upon outcome of the political process in the market regime, namely capitalist cohesion.

\section{Choice of Regime}

In this section, we finally reach the first stage of the model - the decision of what economic regime to be in. In this decision, the agents take into account all the results derived in the previous sections.

In periods of self-sufficiency, agents in the two regions consider the option of starting to trade with each other. However, a transition to a market economy is inevitably associated with transaction costs, as discussed further below. To capture such costs in a simple way, it is assumed that households need to pay a fixed cost, $C>0$, if they start inter-regional trade.

The utility comparison for people in South is

$$
\frac{V_{\mathrm{s}}^{\mathrm{M}}}{V_{\mathrm{s}}^{\mathrm{S}}}=\frac{\alpha\left(R_{\mathrm{s}}^{* *}\right)^{\alpha}\left(R_{\mathrm{n}}^{* *}\right)^{\beta}\left(L_{\mathrm{n}} / L_{\mathrm{s}}\right)^{\beta}}{\Omega_{\mathrm{s}} R_{\mathrm{s}}^{*}}=\frac{\alpha^{\alpha} \beta^{\beta}}{\Omega_{\mathrm{s}}} \frac{\alpha}{\pi}\left(\frac{L_{\mathrm{n}}}{L_{\mathrm{s}}}\right)^{\beta},
$$

where $\left(\alpha^{\alpha} \beta^{\beta}\right) / \Omega_{\mathrm{s}}=\left(\alpha^{\alpha} \beta^{\beta}\right) / \Omega_{\mathrm{n}}>1{ }^{24}$ The equivalent calculation of the net gain of entering a market economy for individuals in North is

$$
\frac{V_{\mathrm{n}}^{\mathrm{M}}}{V_{\mathrm{n}}^{\mathrm{S}}}=\frac{\alpha^{\alpha} \beta^{\beta}}{\Omega_{\mathrm{s}}} \frac{\beta}{1-\pi}\left(\frac{L_{\mathrm{s}}}{L_{\mathrm{n}}}\right)^{\alpha} .
$$

Finally, in the presence of transaction costs $C>0$, we require that the following condition is fulfilled if a transition to a market economy is to occur:

$$
\min \left(\frac{V_{\mathrm{s}}^{\mathrm{M}}}{V_{\mathrm{s}}^{\mathrm{S}}}, \frac{V_{\mathrm{n}}^{\mathrm{M}}}{V_{\mathrm{n}}^{\mathrm{S}}}\right)>1+C .
$$

However, if a transition from a market economy to self-sufficiency were to be considered, there would be no transaction costs in that direction. In

$\overline{{ }^{24} \text { It can }}$ be shown that

$$
\frac{\alpha^{\alpha} \beta^{\beta}}{\Omega_{\mathrm{s}}}=\frac{\alpha^{\alpha} \beta^{\beta}}{\Omega_{\mathrm{n}}}=\left(1+\frac{\beta \gamma_{\mathrm{s}}}{\alpha \delta_{\mathrm{s}}}\right)^{\alpha \delta_{\mathrm{s}}}\left(1+\frac{\alpha \delta_{\mathrm{s}}}{\beta \gamma_{\mathrm{s}}}\right)^{\beta \gamma_{\mathrm{s}}},
$$

which is clearly larger than unity. Furthermore, given the relationships between parameters, it will always be the case that $\Omega_{\mathrm{s}}=\Omega_{\mathrm{n}}$. A formal demonstration can be provided upon request. 
formal terms, there will be a return to self-sufficiency if any one of the two regions prefers to make such a transition:

$$
\min \left(\frac{V_{\mathrm{s}}^{\mathrm{M}}}{V_{\mathrm{s}}^{\mathrm{S}}}, \frac{V_{\mathrm{n}}^{\mathrm{M}}}{V_{\mathrm{n}}^{\mathrm{S}}}\right) \leq 1 .
$$

The interpretation of these conditions is straightforward. Consider, for instance, people in North who make their decision based on equation (15). First, note that a transition to a market economy is more likely if $L_{\mathrm{s}} / L_{\mathrm{n}}$ is high. In the present model, the ratio $L_{\mathrm{S}} / L_{\mathrm{n}}$ is constant and dictated by the initial distribution of the population, because population levels are fixed. Nevertheless, the individuals in North will find the market economy more attractive if the population in South $\left(L_{\mathrm{s}}\right)$ is large relative to their own population $L_{\mathrm{n}}$. This is a supply effect. More Southerners means a greater supply of the agricultural good (relative to the manufactured good), thus implying a lower relative price of the agricultural good that the Northerners are purchasing in the market economy.

Second, the ratio $\beta /(1-\pi)$ represents a political effect. Under selfsufficiency, Southerners' bargaining power is $\pi$. So, the gains for Northerners from shifting into the market economy are higher, the more powerful the other group is. Furthermore, we can observe that the likelihood of a transition to a market economy increases when $\pi$ approaches $1 / 2$ (i.e., when the initial political power is relatively equally distributed). If $\pi$ were to approach 0 or 1 , one of the groups would always object to the transition, and thus this would not occur. ${ }^{25}$

Finally, higher transaction costs, $C$, make trade less likely because, for example, goods need to be physically moved to the marketplace, a monetary system of exchange might be necessary, and common standards need to be agreed upon (North, 1991). The transaction costs for setting up a common market also depend on geography, as emphasized by Gallup et al. (1998). In a broader interpretation, we can think of the transaction costs as depending on how secure private property rights are. Widespread theft and expropriation of revenue add to the transaction costs because some kind of protection against such occurrences then needs to be bought by the market participant. ${ }^{26}$ Finally, the costs of trading could be influenced by animosities between groups, which produces a psychic utility cost of interacting.

\footnotetext{
${ }^{25}$ See Acemoglu and Robinson (2006) for a related discussion of how income inequality, manifested in political inequality, affects the likelihood of a transition to democracy.

${ }^{26}$ Grossman and Kim (1995) have modeled such defensive and offensive expenditures explicitly. Offensive expenditures relate to costs associated with expropriating funds from other individuals. They have shown that under certain circumstances, individuals will refrain from investing in offensive measures, thus motivating scenarios where property rights are secure.
} 


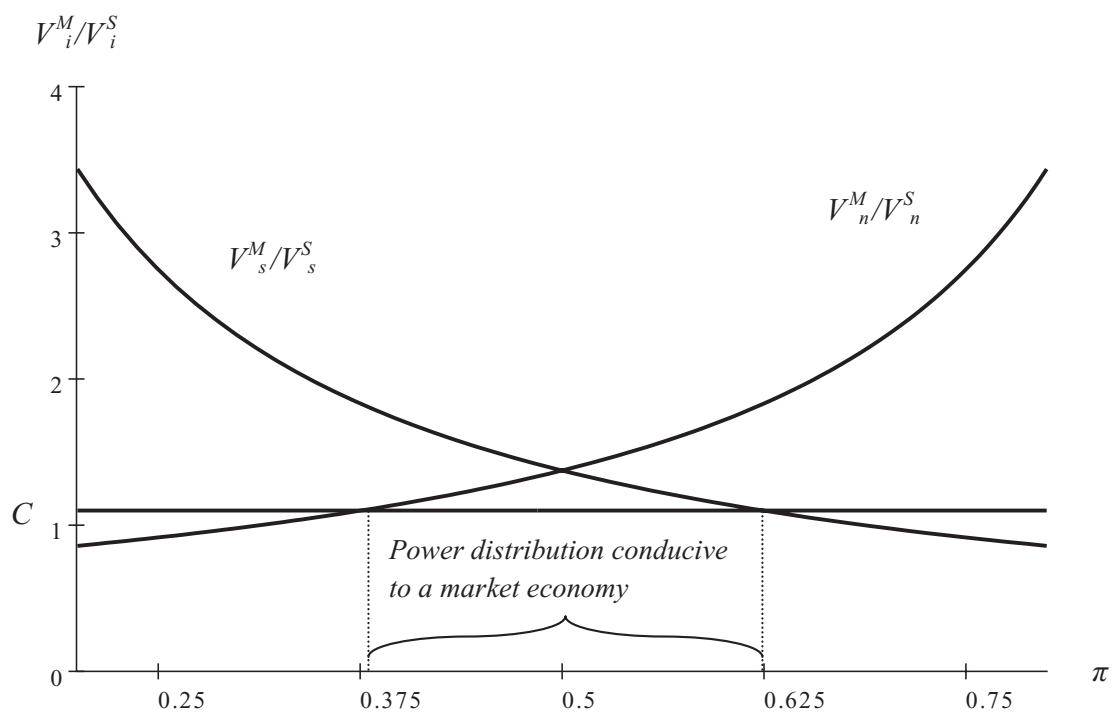

Fig. 2. The impact of power distribution $\mathrm{p}$ on the choice of economic regime. In the simulation, we assume $\alpha=\beta=1 / 2, \gamma_{s}=\delta_{n}=1 / 3, \gamma_{n}=\delta_{s}=2 / 3$, and $C=0.1$, and we assume $L_{n} / L_{s}=1$. See text for interpretations

\section{Discussion}

In Figures 2 and 3, we simulate the choice of market regime for varying distributions of power $\pi$ and population sizes $L_{\mathrm{n}} / L_{\mathrm{s}}$. Throughout this example, we assume that people give an equal weight to consuming manufacturing and agricultural goods $(\alpha=\beta=1 / 2)$, and that comparative advantages are such that $2 / 3=\gamma_{\mathrm{n}}=\delta_{\mathrm{s}}>1 / 3=\gamma_{\mathrm{s}}=\delta_{\mathrm{n}}$. Transaction costs are assumed to be $C=0.1$ so that a transition to a market economy will occur if $V_{\mathrm{s}}^{\mathrm{M}} / V_{\mathrm{s}}^{\mathrm{S}}, V_{\mathrm{n}}^{\mathrm{M}} / V_{\mathrm{n}}^{\mathrm{S}}>1.1$. The figures show the simulated graphs for $V_{\mathrm{s}}^{\mathrm{M}} / V_{\mathrm{s}}^{\mathrm{S}}$ and $V_{\mathrm{n}}^{\mathrm{M}} / V_{\mathrm{n}}^{\mathrm{S}}$ as functions of $\pi$ and $L_{\mathrm{n}} / L_{\mathrm{s}}$, respectively.

As indicated by Proposition 1 and 2, we can see that Southerners' interest in taking part in a market economy is large if their own bargaining power $\pi$ is small, but decreases as $\pi$ increases. When $\pi>0.625$, Southerners no longer find it worthwhile to be in a market economy because they are powerful enough to obtain a lot of resources under self-sufficiency. Similarly, North loses interest in the market economy when $\pi<0.375$. However, given a relatively equal power distribution, both regions will prefer a market economy. In the example, this will entail dividing up $R$ so that $R_{\mathrm{n}}^{*}=R_{\mathrm{s}}^{*}=R / 2$. With an unequal bargaining power, such that, for instance, $\pi=0.25$, Southerners will be very interested in a market economy 


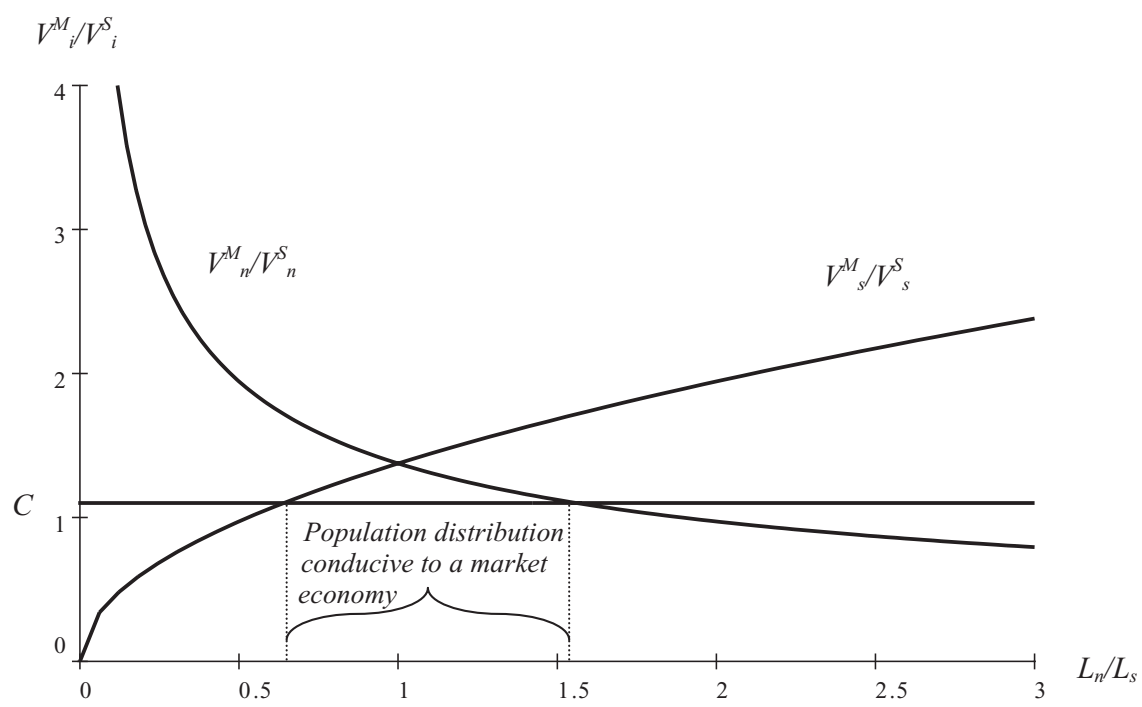

Fig. 3. The impact of population proportions $\left(L_{n} / L_{s}\right)$ for the choice of economic regime. In the simulation, we assume $\alpha=\beta=1 / 2, \gamma_{s}=\delta_{n}=1 / 3, \gamma_{n}=\delta_{s}=2 / 3$, and $C=0.1$ and we set $\pi=1 / 2$. See text for interpretations

whereas Northerners will not, and hence both will end up producing in isolation.

Figure 3 shows the importance of the relative size of the population $L_{\mathrm{n}} / L_{\mathrm{s}}$ for a market economy to arise, assuming that the power distribution is initially perfectly equal $(\pi=1 / 2)$. Northerners' interest in participating in a market economy is very high when their own population is relatively small, and then falls with $L_{\mathrm{n}} / L_{\mathrm{s}}$. When North's population is about 50 percent larger than that of South, the former opt out of the market economy. Southerners prefer self-sufficiency when $L_{\mathrm{n}} / L_{\mathrm{s}}<2 / 3$. Just as with the distribution of bargaining power, a market is most likely to emerge when population levels are not too different.

Transaction costs $C$ also play a critical role in this highly simplified setting. We can easily infer from both figures that a relatively high $C$ implies that the range where a market economy is feasible is very small. During periods of weak property rights and high costs of transport, even equally large and powerful regions will choose to produce in autarky. In Western Europe, the centuries following the collapse of the Roman Empire in the fifth century are an example of such a period. The gradual improvement of property rights and means of transportation during the late Medieval period implied a lowering of $C$ and a return of market exchange. 
The transition from self-sufficiency to a market economy typically has major consequences for how societies are organized. Economic interdependence between regions and groups arises via the price mechanism. This change transforms the nature of the political struggle, because it is no longer in the interest of a previously powerful region or group to provide its opponents with less than their due share of the economy's resource. If one group has too few resources, the prices of goods that are consumed in both regions will rise. As a result, the optimal choice for both political groups will be to reach a compromise - the Pareto optimal allocation of the resource - which maximizes aggregate output. Moreover, this allocation is unanimously agreed upon; a sense of political cohesion emerges and, moreover, prosperity increases as a result of specialization.

While cohesion and prosperity should thus be positively correlated, it is worth observing that the link could be violated in a cross-country context. To illustrate, consider two different countries. One is richer than the other, yet this difference in productive capabilities might not necessarily be tradeinduced. Indeed, one economy could be relatively richer because of a larger supply of natural resources, $R$. Because the market transition depends on the relative, and not absolute, levels of productivity across individuals, the richer economy could be in a no-trade regime, while the poorer economy could be organized as a market economy with full specialization. Although this example is perhaps too contrived to be regarded as the likely configuration of prosperity and cohesion, it serves to highlight the following important point. Merely raising the income of an economy (i.e., by infusing foreign aid or finding oil) will not lead to a more cohesive political climate, unless this increase of productivity is associated with an intensified exchange of goods between citizens.

Could there be a reversal from a capitalist market economy back to self-sufficiency in our model, perhaps because of an exogenous shock? Expressions (14) and (15) suggest some shocks that could possibly cause a collapse of the market economy. If, for instance, the population ratio $L_{\mathrm{s}} / L_{\mathrm{n}}$ fell, perhaps because of disease, mass starvation, or emigration from the South, the price of agricultural goods would rise as a result of the fall in supply. From equation (15) and Figure 3, we see that if this change were large enough, then Northerners might be induced to switch back to self-sufficiency.

The same effect might certainly arise if transaction costs $C$ increased, perhaps because of the general insecurity caused by a war in a neighboring country, or a sudden exogenous rise in oil prices, leading to higher transportation costs. We know that several such reversals have occurred in the recent millennia. 


\section{Concluding Remarks}

In this paper, we have developed the hypothesis that economic interaction between agents, the exchange of goods, is crucial for the nature of political outcomes. In particular, we have described a possible trajectory along which an economy might travel in the course of development into a regime where political cohesion prevails. The implied link between income and political cohesion is broadly consistent both with modern-day evidence on affluence and stability and with the historical record of current-day developed economies.

The model is, needless to say, highly stylized. For example, it only allows for two rival political factions. In principle, the framework could be generalized to the case of $N$ groups (politically engaged in generalized Nash bargaining) with individually specific comparative advantages. This would potentially allow for regimes involving partial specialization (some groups are trading and others are not), thus capturing a more gradual process of market integration. The model might also be extended to a dynamic setting where players take into account the future consequences of current decisions.

The basic idea put forward in this paper could be applied to other areas of interest. A line of inquiry where the logic of the model might apply is the sustainability of democracy. It might be conjectured that the persistence of democracy requires certain amounts of political cohesion between rival political parties. In the absence of a fully developed market economy, democratic institutions might allow a majority to treat a minority unfairly, leading the latter to hold a grievance. Conversely, if political factions are economically integrated, political cohesion arises, leading to policy choices with broad public support, thus making democratic institutions relatively uncontroversial from the perspective of individual citizens of society. While economic integration allows for higher income per capita, because gains from specialization are exploited, the key driving force behind cohesion is the interdependence of individuals via the market. Income does not matter per se, contrary to the so-called modernization hypothesis (Lipset, 1959). ${ }^{27}$ Perhaps it was not a coincidence that democratic institutions spread across Western Europe following the industrious revolution? Our model might form a basic framework for further research in this area.

\footnotetext{
${ }^{27}$ See Boix (2003) for an inspired analysis of democratic transitions, highlighting the importance of inequality and asset mobility for the emergence and viability of democratic institutions.
} 


\section{References}

Acemoglu, D. and Robinson, J. (2000), Why Did the West Extend the Franchise?, Quarterly Journal of Economics 115, 1167-1199.

Acemoglu, D. and Robinson, J. (2006), Economic Origins of Dictatorships and Democracy, MIT Press, Cambridge, MA.

Aidt, T. and Sena, V. (2005), Unions: Rent Extractors or Creators, Scandinavian Journal of Economics 107, 103-121.

Alesina, A. and La Ferrara, E. (2002), Who Trusts Others?, Journal of Public Economics 85, 207-234.

Alesina, A. and Perotti, R. (1996), Income Distribution, Political Instability, and Investment, European Economic Review 40, 1203-1228.

Alesina, A., Özler, S., Roubini, N., and Swagel, P. (1996), Political Instability and Economic Growth, Journal of Economic Growth 1, 189-211.

Annett, A. (2001), Social Fractionalization, Political Instability and the Size of Government, IMF Staff Papers 48, 561-592.

Archer, J. E. (2000), Social Unrest and Popular Protest in England 1780-1840, Cambridge University Press, Cambridge.

Barro, R. J. (1991), Economic Growth in a Cross-Section of Countries, Quarterly Journal of Economics 106, 327-369.

Binmore, K., Rubinstein, A., and Wildavsky, A. (1986), The Nash Bargaining Solution in Economic Modelling, Rand Journal of Economics 17, 176-188.

Boix, C. (2003), Democracy and Redistriction, Cambridge University Press, Cambridge.

Britnell, R. H. (1993), The Commercialisation of English Society 1000-1500, Cambridge University Press, Cambridge.

Caselli, F. and Gennaioli, N. (2008), Economics and Politics of Alternative Institutional Reforms, Quarterly Journal of Economics 123, 1197-1250.

Clark, G. (1996), The Political Foundations of Modern Economic Growth: England 1540-1800, Journal of Interdisciplinary History 26, 563-588.

Clark, G. and Van der Werf, Y. (1998), Work in Progress? The Industrious Revolution, Journal of Economic History 58, 830-843.

Collier, P. and Hoeffler, A. (2004), Greed and Grievance in Civil War, Oxford Economic Papers 56, 563-595.

De Vries, J. (1976), The Economy of Europe in the Age of Crisis, 1600-1750, Cambridge University Press, Cambridge.

De Vries, J. (1994), The Industrial Revolution and the Industrious Revolution, Journal of Economic History 54, 249-270.

Easterly, W. (2002), The Elusive Quest for Growth - Economists' Adventures and Misadventures in the Tropics, MIT Press, Cambridge, MA.

Easterly, W. and Levine, R. (1997), Africa's Growth Tragedy: Politics and Ethnic Division. Quarterly Journal of Economics 112, 1203-1250.

Friedman, B. (2005), The Moral Consequences of Economic Growth, Vintage Books, New York.

Galor, O and Moav, O. (2006), Das Human Kapital: A Theory of the Demise of the Class Structure, Review of Economic Studies 73, 85-117.

Galor, O., Moav, O., and Vollrath, D. (2009), Land Inequality and the Emergence of Human Capital Promoting Institutions, Review of Economic Studies 76, 143-179.

Gallup, J. L., Sachs, J., and Mellinger, A. (1998), Geography and Economic Development, NBER Working Paper 6849.

Gartzke, E. (2007), The Capitalist Peace, American Journal of Political Science 51, 166-191. 
Glaeser, E. (2005) The Political Economy of Hatred, Quarterly Journal of Economics 120, $45-86$.

Grossman, H. and Kim, M. (1995), Swords or Plowshares? A Theory of the Security of Claims to Property, Journal of Political Economy 103, 1275-1288.

Guiso, L., Sapienza, P., and Zingales, L. (2003), People's Opium? Religion and Economic Attitudes, Journal of Monetary Economics 50, 225-282.

Guiso, L., Sapienza, P., and Zingales, L. (2008), Alfred Marshall Lecture Social Capital as Good Culture, Journal of the European Economic Association 6, 295-320.

Hodges, R. (1982), Dark Age Economics - The Origins of Towns and Trade AD 600-1000, Duckworth, London.

Lindqvist, E. and Östling, R. (2010), Political Polarization and Economic Performance, American Political Science Review 104, 543-565.

Lipset, M. S. (1959), Some Social Requisites of Democracy: Economic Development and Political Legitimacy, American Political Science Review 53, 69-105.

Miguel, E., Satyanath, S., and Sergenti, E. (2004), Economic Shocks and Civil Conflict: An Instrumental Variables Approach, Journal of Political Economy 112, 725-753.

Mousseau, M. (2003), The Nexus of Market Society, Liberal Preferences, and Democratic Peace: Interdisciplinary Theory and Evidence, International Studies Quarterly 47, 483-510.

Mousseau, M., Hegre, H., and Oneal, J. (2003), How the Wealth of Nations Conditions the Liberal Peace, European Journal of International Relations 9, 277-314.

North, D. (1991), Institutions, Journal of Economic Perspectives 5, 97-112.

Olson, M., Jr (1963), Rapid Growth as a Destabilizing Force, Journal of Economic History 23, 529-552.

Olsson, O. (2007), Conflict Diamonds, Journal of Development Economics 82, 267-286.

Seabright, P. (2004), The Company of Strangers - A Natural History of Economic Life, Princeton University Press, Princeton, NJ.

Skaperdas, S. and Syropoulos, C. (2001), Guns, Butter, and Openness: On the Relationship between Security and Trade, American Economic Review, Papers and Proceedings 91 (2), 353-357.

Tilly, C. (1995), Popular Contention in Great Britain, 1758-1834, Harvard Univ. Press, Cambridge, MA.

Voth, H.-J. (1998), Time and Work in Eighteenth Century London, Journal of Economic History 58, 29-58.

First version submitted May 2010;

final version received September 2011.

(C) The editors of The Scandinavian Journal of Economics 2013. 